Nigeria Journal of Pure and Applied Physics

Vol. 10(1), 1 - 7, 2020

OPhysics Department, Federal University of Technology Akure

DOI: 10.4314 njpap.v10i1.1

\title{
Use of spectral decomposition technique for mapping geologic features of 'Reigh' field, Onshore Niger Delta
}

\author{
O. K. Olaleye ${ }^{\dagger}$, P. A. Enikanselu, M. A. Ayuk \\ Department of Applied Geophysics, The Federal University of Technology, Akure, Nigeria \\ ${ }^{\dagger}$ Corresponding Author's Email: kolaleyeolomo@gmail.com
}

\begin{abstract}
Spectral Decomposition Technique based on Short-Window Discrete Fourier Transform (SWDFT) was applied to threedimensional (3D) seismic data obtained from 'Reigh' field, onshore Niger Delta with a view to enhancing stratigraphic interpretation for geological features which are beyond seismic resolution. Two sands units from the study area were studied to produce spectrally decomposed surfaces. The result of the study revealed thin bed layer at the centre of the field on sand unit 'A'. Sand-filled meandering channel was detected and highlighted in the northern part of sand unit 'B' based on Red-Green-Blue frequency modulation of spectral decomposition. The study has enhanced geologic understanding of the field by improving thin bed resolution, highlighting geologic features and displaying bed thickness variation of studied sand units in the study area.
\end{abstract}

Keywords: geologic features, Niger Delta, seismic data, spectral decomposition

\section{INTRODUCTION}

Exploration geophysical methods utilize the science of natural forces and phenomenon of the earth in evaluating the physical processes and properties of the subsurface, particularly as they are applied to a wide range of investigation for societal and human needs [1], [2]. In hydrocarbon exploration, potential (gravity and magnetic), seismic and electromagnetic methods are mainly employed [3]. Magnetic, gravity and seismic methods measure the variations in the magnetic, density and acoustic properties of a geologic medium respectively. These variations measurement enables the mapping of gross geologic and stratigraphic features that are associated with the petroleum system of a basin, with the motive to studying its geologic history and likelihood of hydrocarbon generation and accumulation on a large scale basis [3], [4]. In addition, the reflection data of seismic method provides subsurface reflections, directly correlating to the physical properties of geologic strata at depth that reflects their local subsurface geology [2], therefore helps in characterizing distribution and physical properties of a reservoir on a field scale basis [5]. Electromagnetic methods are useful for detecting and monitoring hydrocarbon by measuring resistivity changes over geologic features already delineated by seismic surveys [6], [7]. Seismic survey is therefore apparently the most important technique in all stages of hydrocarbon production and development [8], [9].

Seismic data comprised of overprinted wavelet, resulting from frequent spanning of several subsurface layers during acquisition, therefore generating a complex tuned seismic reflection data. This varying frequency content in time makes seismic data non-stationary in nature [10]. The tuning effects of seismic data, together with subsurface lateral and vertical heterogeneity of sand distribution, affect the interpretation of some geologic features using conventional form of seismic structural interpretation. Geologic character responds differently to different frequency ranges of the seismic signal, depending on the mode and frequency at which the geologic features were deposited. Therefore, certain geologic features are more visible and interpretable at some specific frequencies or frequency range. Spectral decomposition technique aims to delineate these subtle geologic features, by characterizing the time-dependent frequency response of the subsurface rocks [10], discretizing the complexly tuned reflection and boosting the higher frequency content from the seismic data.

Spectral decomposition has been used over the years as a way of qualitatively interpreting seismic data [11], [12], [13], [14], [15], [10]. Spectral decomposition is used in detecting stratigraphic features, such as channels, and thin beds beyond seismic resolution. Mapping geologic features require the specification of the geometry, facies changes in terms of bedding thickness and physical properties of the geologic formations. According to [15], spectral attributes are applicable beyond the detection of thin beds but also in delineation of internal architecture of reservoir sands by higher signal resolution, to highlight hidden geologic features and their geometry for the possibility of hydrocarbon prediction [14]. More so, stratigraphy resonates at wavelengths dependent on the bedding thickness [10], bedding thickness could also be predicted quantitatively using spectral decomposition.

This research was carried out in order to improve geological understanding in the Reigh Field in delineating stratigraphic features that requires higher seismic resolution and interpretation, which could serve as pathfinder for potential hydrocarbon reservoir within the field of study.

\section{GEOLOGICAL FRAMEWORK}

The study area is an onshore oil field in the Niger Delta Basin, located in the south-western part of Nigeria (Figure 1). The Niger Delta is located between Latitudes $4^{0}$ and $6^{0} \mathrm{~N}$ 


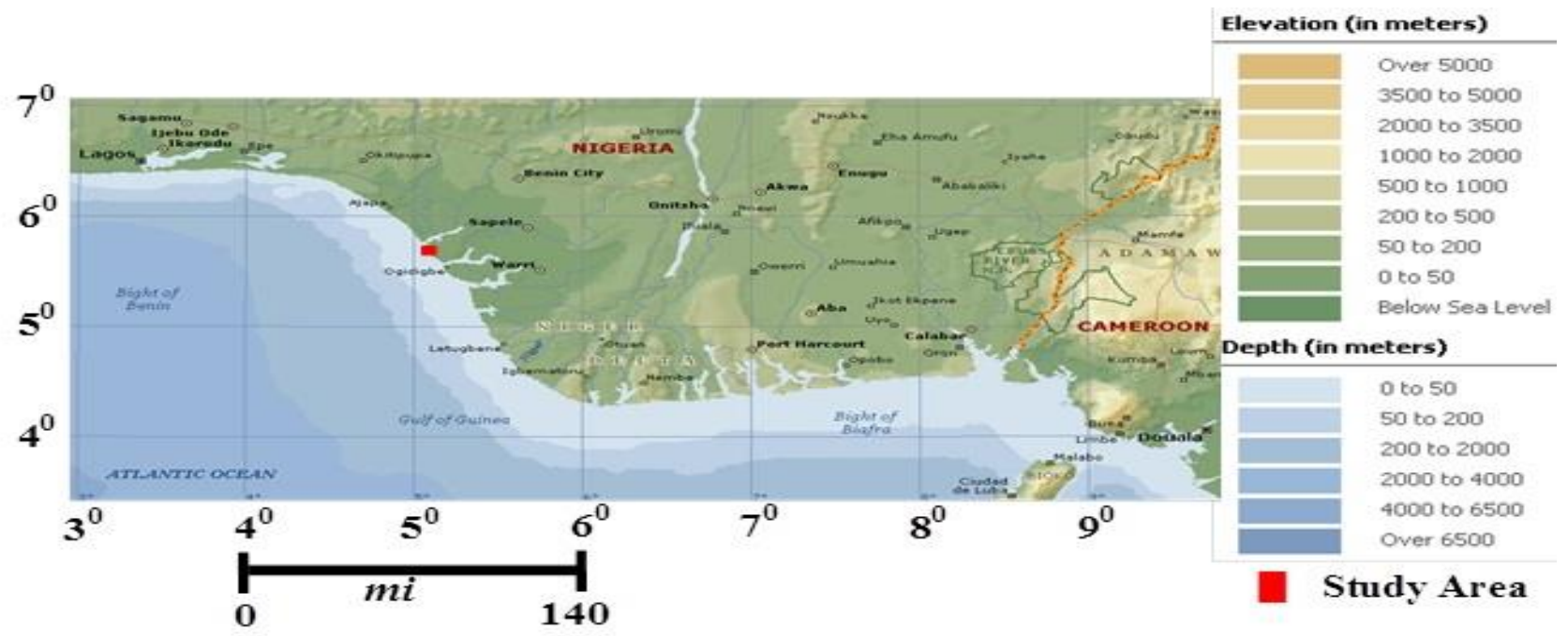

Fig. 1. Map of Niger Delta showing the study area (after [22])

and between Longitude $3^{0}$ and $9^{\circ} \mathrm{E}[16]$. It is situated at the apex of the Gulf of Guinea on the West Coast of Africa. The Niger Delta Basin is one of the most prolific deltaic hydrocarbons provinces in the World. The Niger Delta comprises of time-equivalent, proximal to distal, prograding facies units of Benin, Agbada, and Akata Formations, which are represented by a typical offlap sequence, distinguished mostly based on their sand-shale ratios [17]. The deepmarine pro-delta Akata Formation [18] composed of thick shale sequences, which is the potential source rock of the Niger Delta. Overlain by Akata Formation represents the actual deltaic portion, which has been the target for hydrocarbon reservoirs in the Niger Delta Basin. Finally, overlain by the delta-top Benin Formation, which consists of alluvial and upper coastal plain sands. The Niger Delta

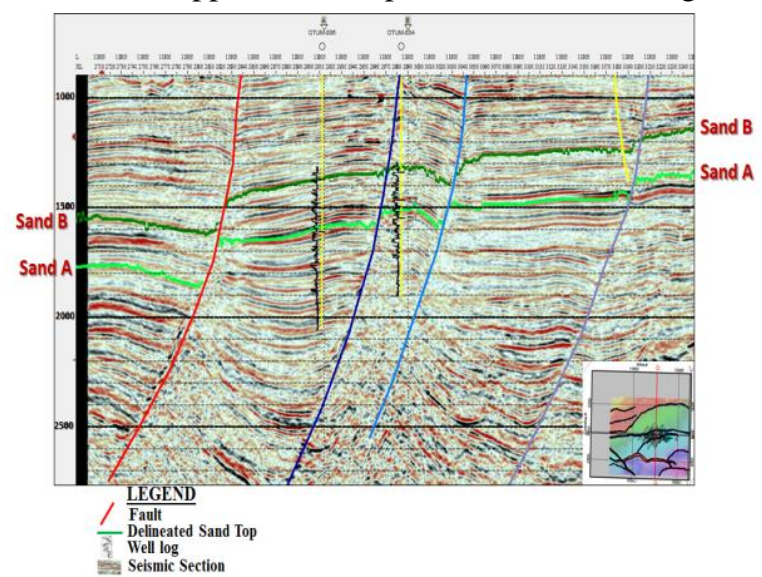

Fig. 2. Seismic section showing the positions of faults and map horizons of delineated sand units of the study area structural trapping elements include those associated with simple rollover structures, structures with multiple growth faults, structures with antithetic faults, and collapsed crest structures [19]. On the flanks of the delta, stratigraphic traps are likely as important as structural traps [20]. Most of the turbidite oilfields also have some degree of stratigraphic control, either by reservoir pinchout, crestal accumulations below erosional surfaces and/or partial mud-filled channels.

\section{THEORY}

The use of short window discrete Fourier transform (SWDFT), also known as transform using constant size windows, to generate spectral balancing for the purpose of seismic interpretation was first demonstrated by [11], creating Morlet wavelets. The Morlet wavelets are good approximation to real seismic wavelets. Also, the first demonstration of spectral decomposition using SWDFT in interpreting 3D seismic data volumes to generate common frequency cubes was done by [12].

Spectral Decomposition requires the transformation of each individual 1D seismic trace, [s (t)] into a 2D timefrequency representation, $[\mathrm{s}(\tau, \omega)]$. The equation for the short window discrete Fourier transform (SWDFT) is given in eq. 1 [21].

$$
U_{S W D F T}(\tau, f)=\frac{1}{\sqrt{2 \pi}} \int u(t) W(t-\tau) e^{-j 2 \pi f t} d t
$$

where $u(t)=\sum_{j} a_{j} \cdot w\left(t-t_{j}, f_{j}, \varphi_{j}\right)+$ Noise is the seismic data time trace $\left(a_{j}, t_{j}, f_{j}\right.$ and $\phi_{j}$ represent the amplitude, centre time, peak frequency, and phase of the $j^{\text {th }}$ wavelet $w$, respectively), $\tau$ is the centre time of the window function $\mathrm{W}(\mathrm{t}$ 
$-\tau)$, $\mathrm{f}$ is the frequency, and $\mathrm{U}_{\mathrm{SWDFT}}(\tau, \mathrm{f})$ is the timefrequency function. The window function $W(t-\tau)$ can be either a tapered or untampered rectangular window (boxcar), Gaussian window, Hamming window, or Hanning window.

\section{MATERIALS AND METHODS}

A post stacked, migrated, zero phased and spectrally balanced three-dimensional (3D) seismic volume with bandwidth of $0-125 \mathrm{~Hz}$ was used as input data for the study. The 3D seismic data volume consists of 700 Inlines and 550 Crosslines with 25m line spacing. Mapped horizons of two sand units delineated from borehole logs of the field (Figure 2) were also used as input.

Matching pursuit spectral decomposition algorithm [23] was used. Brute force scans over all times and frequencies were done to generate spectral frequency distribution of the seismic data amplitude over the study area. Short-Window Discrete Fourier Transform (SWDFT) was used to generate discrete frequency cubes by transforming the time-domain seismic data to frequency domain. This replaces the single seismic input trace with a gather of traces corresponding to the Spectral Decomposition of the input data (seismic volume). The application of the SWDFT was used, on a trace by trace basis, to create spectral decomposition volumes. Seven discrete frequency cubes were generated within frequency range of 8 to $64 \mathrm{~Hz}$, each one representing a different frequency band. The input horizons of the two delineated sand units were extracted from the output tuning cubes of the discretized seismic volumes to generate decomposed common frequency horizons of the sand units. The decomposed common frequency horizons of the sand units were viewed to identify textures and geological patterns. Horizon maps of the generated seven discrete frequencies were animated through and three of the maps with spatial patterns corresponding to reasonable geological models were chosen for further analysis. The chosen three discrete frequencies of spectrally decomposed surfaces were blended by plotting them against red, green, blue (RGB) colour scheme to interpret seismic facies distribution of the sand units based on frequency variations. RGB blending gives an effective use of colour in encoding information for detailed and highly intuitive visualization. In the RGB display, each input discrete spectral volume is mapped individually to the red, green and blue monochromatic components of RGB space. The intensity of each colour represents the contribution of the assigned spectral frequency band in the sand unit [24], [25]. Using the RGB blend, geological features, thin beds and thickness variations were interpreted through spatial pattern recognition. The period $(\mathrm{T})$ of a wave is increased within a thick medium. At high frequency, the period (T) as well as the wavelength $(\lambda)$ of the seismic wave is small (Eqs. 2 and 3), therefore causing an increase in the vertical resolution and as such, highlighting thin reservoir layers.

$$
\begin{aligned}
& f=1 / T \\
& f=v / \lambda
\end{aligned}
$$

Where $\mathrm{v}$ is the seismic wave velocity $(\mathrm{m} / \mathrm{s}) ; \lambda$ is the wavelength $(\mathrm{m})$ and $\mathrm{T}$ (Period) is time taken for one complete cycle (sec)

\section{RESULTS AND DISCUSSION}

Figure 3 shows the extracted spectral frequency distribution of the seismic data amplitude over the study area. Figure 3 isolates the tuning effects of the spectral frequency relating to the geology of the field from that of the input seismic wavelet. Observation on Figure 3 shows that the seismic data have a seismic frequency range of 8 to $64 \mathrm{~Hz}$ relating to the geology of the field while frequency due to background/noise effect is from $64 \mathrm{~Hz}$ up to $125 \mathrm{~Hz}$. The magnitude of reflection within the seismic frequency range (Figure 3) revealed that the geology of the area is characterized mainly by low frequency deposition.

Figure 4 is the seven generated spectral decomposition surfaces at different frequency ranges of sand unit ' $A$ '. In this display, Figure $4 \mathrm{a}-\mathrm{g}$ are individual spectral components range. In a frequency spectrum, peak frequency slightly increases as the layer thickness decreases [26]. Also, tuning thickness is inversely proportional to the peak spectral frequency of a broadband spectral response [27]. Therefore, geological features are expected to be thicker at lower frequency range. The display on Figure 4a revealed that most of the geology of sand unit ' $A$ ' is beyond $16 \mathrm{~Hz}$. The northeast part of Figure 4a (zone ' $A$ '), have geologic feature with frequencies below $10 \mathrm{~Hz}$. This part is the thickest part of sand unit ' $A$ '. Figure $4 \mathrm{~b}$ revealed that the centre part of sand ' $A$ ' (zone ' $B$ ') is characterized by spectral frequency

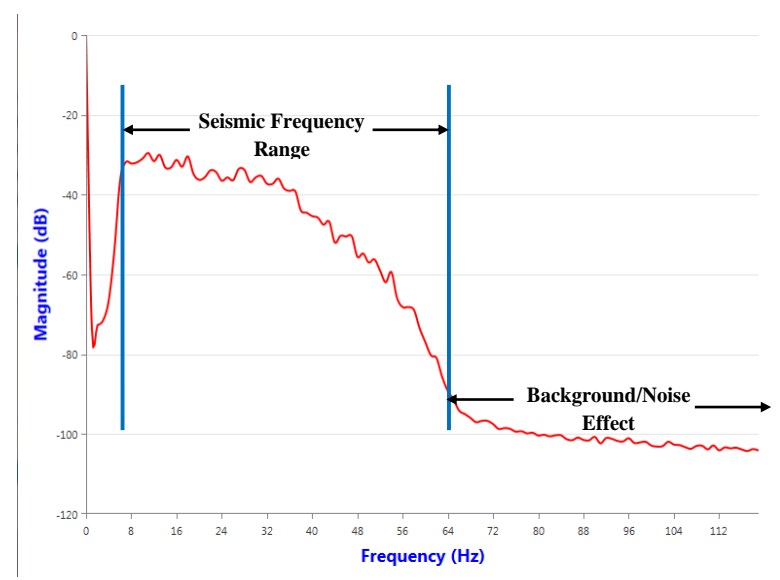

Fig. 3. Spectral frequency distribution of the seismic data amplitude over the study area. 

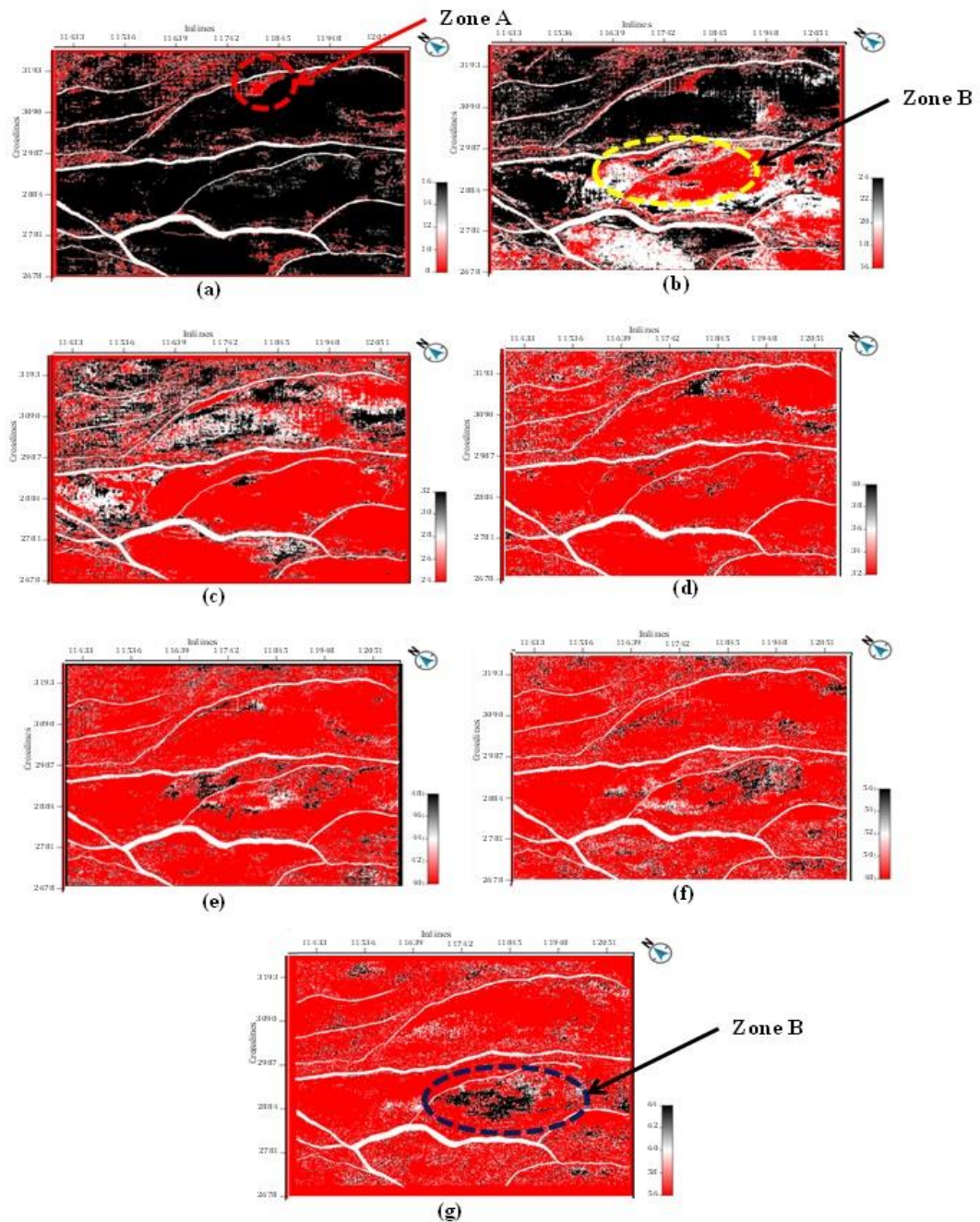

Fig. 4. Spectral Decomposition for Sand A, (a) Dominant Frequency 8-16Hz; (b) 16-24Hz; (c) 24-32Hz; (d) 32-40Hz; (e) 40-48Hz; (f) $48-56 \mathrm{~Hz}$; (g) $56-64 \mathrm{~Hz}$.

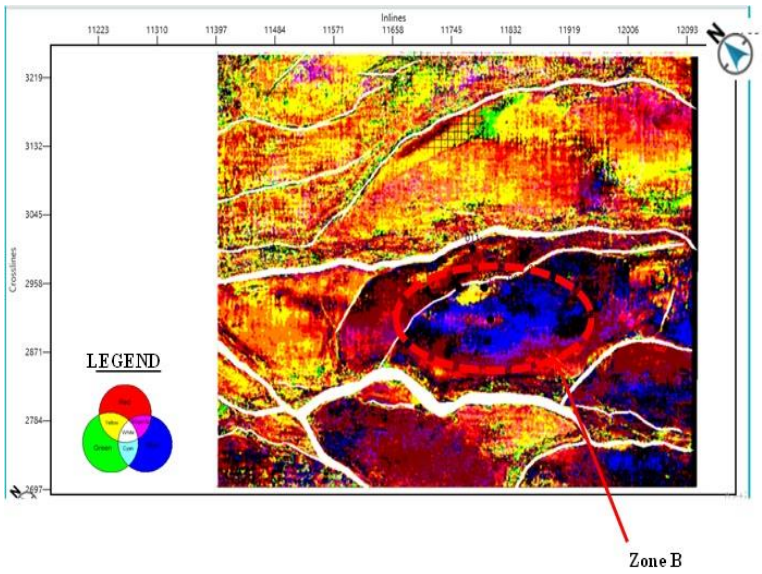

Fig. 5 . RGB Blend of Spectral Decomposition 8-16 Hz (Red), $24 \mathrm{~Hz}$ (Green) and 56-64 Hz (Blue) for Sand A below $20 \mathrm{~Hz}$ indicating that this area is thick compared to the other parts with frequency beyond $24 \mathrm{~Hz}$. The delineated thick portions within Figure $4 \mathrm{a}$ and $\mathrm{b}$ indicate thick geologic features which could harbour hydrocarbon, if structurally conformable and with high amplitude anomaly. Other significant areas on sand unit 'A' are the areas with thin beds as represented by black colour on Figures $4 \mathrm{e}, \mathrm{f}$ and $\mathrm{g}$. Special consideration is in the centre part of Figure $4 \mathrm{~g}$, which displays spectral frequency beyond $64 \mathrm{~Hz}$, a thin bed within the sand unit. From Figure 4, the three geological significant amplitude surfaces are frequency range 8 to $16 \mathrm{~Hz}$ (Figure 4a), 16 to $24 \mathrm{~Hz}$ (Figure 4b) and 56 to $64 \mathrm{~Hz}$ (Figure 4g). These three quantities are combined to give a single image (Figure 5).

Figure 5 is an RGB blend of the three geological significant frequency surfaces and it reveals that thickest area of sand unit ' $A$ ' appears as brown/orange, the less thick as green/yellow and the thin areas as blue. Observation on 


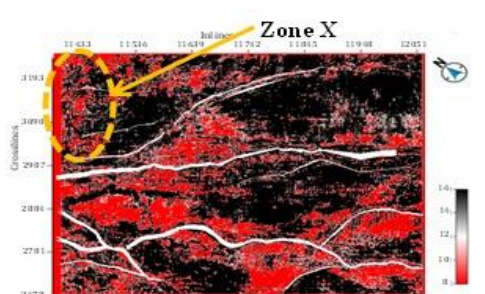

(a)

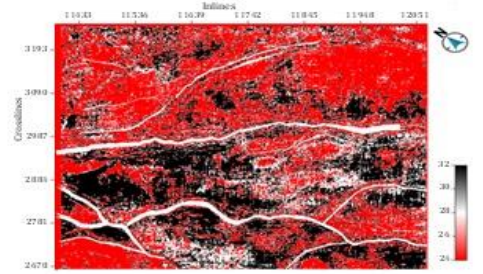

(c)

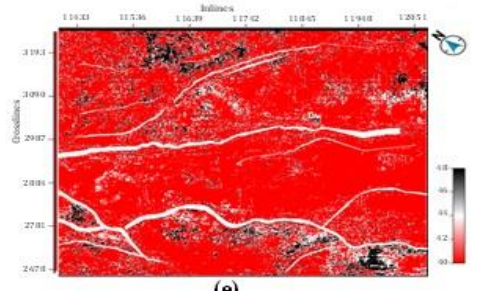

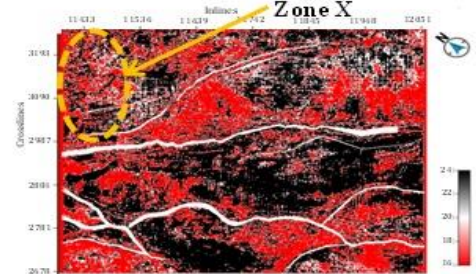

(b)

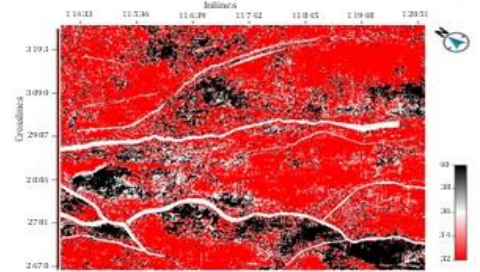

(d)

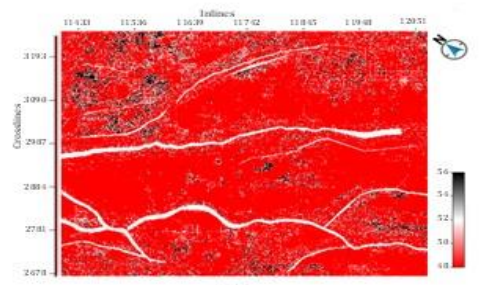

(f)

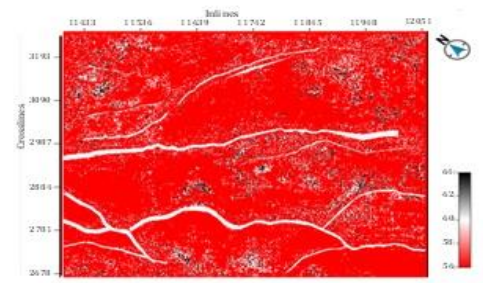

$(\mathrm{g})$

Fig. 6. Spectral Decomposition for Sand B, (a) Dominant Frequency 8-16Hz; (b) $16-24 \mathrm{~Hz}$; (c) $24-32 \mathrm{~Hz}$; (d) $32-40 \mathrm{~Hz}$; (e) 40-48Hz; (f) $48-56 \mathrm{~Hz}$; (g) $56-64 \mathrm{~Hz}$.

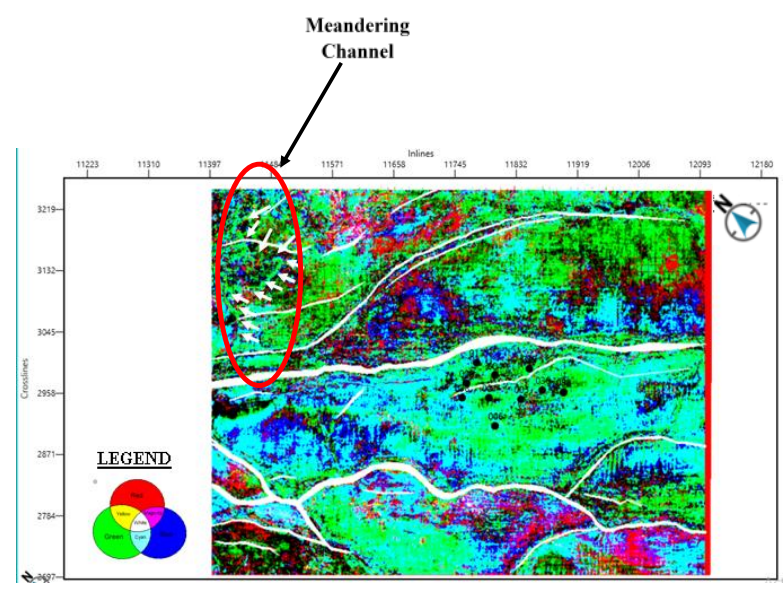

Fig. 7. RGB Blend of Spectral Decomposition Dominant Frequency for Sand B, Frequencies 8-16 Hz (Red), 16-24 Hz (Green) and 24-32Hz (Blue).
Figure 5 shows that the centre of the field is thick, with some patches of thin layer to the west. This was interpreted on the basis of brown spectral appearance at the centre, overlain by blue to the south-western part of the field. The presence of the thin layer of frequency $56-64 \mathrm{~Hz}$ indicates that the sand unit is stacked, with a thin sand layer at the top. The thin layer at the centre, if geologically conformable with high amplitude anomaly, may be significant for hydrocarbon accumulation and production in the field.

Figure 6 is the generated spectral decomposition surfaces at different frequency ranges of sand unit ' $\mathrm{B}$ '. Here, there is no thin layer beyond the seismic resolution as observed on Figure 6g. This is because black colour spectral patched, which are expected to characterize thin layer beyond $64 \mathrm{~Hz}$ frequency, is not evident on the sand unit (Figure $6 \mathrm{~g}$ ). The zone labelled ' $\mathrm{X}$ ' in the northern part of Figure 6 a shows a narrow band of low frequency seismic amplitude to the west. This narrow band widens on Figure 6b, which latter 
disappears on Figure 6c. The observation on zone ' $\mathrm{X}$ ' is an indication of a geologic feature. Modulation of frequency ranges through the RGB blending (Figure 7) gave a better interpretation of the sand unit ' $\mathrm{B}$ ' and the geological feature within zone ' $\mathrm{X}$ ' was better revealed. Figure 7 is the RGB colour blend of the three most geological significant frequency ranges (Figure 6a-c) of sand unit ' $\mathrm{B}$ '. The northern corner of Figure 7 (zone ' $X$ ') provides more information on the stratigraphy of sand unit ' $\mathrm{B}$ ' by mapping out a channel/levee deposit by the characteristic low frequency values along the channel deposit. There is a strong correlation between channel thickness and spectral amplitude [28], which makes the channel easy to map on spectral amplitude map on the bases of thickness variation and spatial patterns corresponding to the geological feature. This deposit continues towards the western side of the field indicating NE channel axis. This channel is a meandering type inferring geology interpretation of a low energy meandering depositional process around the area.

\section{CONCLUSION}

Short-Window Discrete Fourier Transform (SWDFT) was applied to three-dimensional (3D) seismic data obtained from 'Reigh' field, Onshore Niger Delta to produce spectrally decomposed surfaces of the field. Two sand units were interpreted using the spectral decomposition technique. The isolation of the tuning effects of the 3D seismic data revealed that the geology of the area is characterized mainly by low frequency deposition, indicating thick sands. Individual spectral decomposition surfaces generated for each sand unit revealed different geologic features and varying thicknesses at different frequency between 8 and 64 $\mathrm{Hz}$.

The result obtained from the RGB blend revealed, through spatial pattern recognition and thickness variation, that the centre part of sand ' $A$ ' is characterized by thick sand deposit/geologic feature overlain by thin bed, which was interpreted as stacked sand unit within the field. A channel/levee deposit was delineated at the northern corner of sand unit ' $\mathrm{B}$ ' distinguished mainly by characteristic low frequency along the channel deposit. The channel was interpreted to be thick with its channel axis toward NE direction of the field. The delineated geologic features on both sand units 'A' and 'B' may be significant for hydrocarbon accumulation and production in the field, if geologically conformable with high amplitude anomaly [15].

The analysis of seismic amplitude response at different frequencies and its RGB blend prove to be adequate in enhancing stratigraphic interpretation for geological features and characterizing sand units based on thickness variation.

\section{REFERENCES}

[1] Sherriff, R. E., 'Geophysics' in Encyclopedic Dictionary of Exploration Geophysics (3rd ed.), Society of Exploration Geophysics, 400p, 1991.

[2] Kearey, P., Brooks, M. and Hill, I., An Introductory to Geophysical Exploration. Oxford, London, Blackwell Scientific Publications, 262p, 1984.

[3] Sengbush, R. L., Geophysical Exploration for Hydrocarbon. In R. L. Sengbush, Petroleum Exploration: A Quantitative Introduction. Springer, Dordrecht, pp55, 1986.

https://doi.org/10.1007/978-94-009-4554-8_3

[4] Beigert, E. K., From Black Magic to Swarms: Hydrocarbon Exploration using Non-seismic Technologies. Conference Proceedings. EAGE Workshop on Non-seismic Methods, cp-93-00022, 2008.

[5] Zeng, H., Strata Slicing: Benefits and Challenges. The Leading Edge, 29(9): 1040-1047, 2010. https://doi.org/10.1190/1.3485764

[6] Younis, A., El-Qady, G., Abd Alla, M., A del Zaher, M., Khalil, A., Al Ibiary, M. and Savaev, A., AMT and CSAMT Methods for Hydrocarbon Exploration at Nile Delta, Egypt. Arabian Journal of Geosciences, 8(4): 1965-1975, 2015. https://doi.org/10.1007/s12517-014-1354-6

[7] Streich, R., Controlled-Source Electromagnetic Approach for Hydrocarbon Exploration and Monitoring of Land. Surveys in Geophysics, 37(1):47-80,2016. https://doi.org/10.1007/s10712-015-9336-0

[8] Mondol, N. H. and Bjorlykke, K., Petroleum Geoscience: From Sedimentary Environment to Rock Physics. Springer-Verlag, pp 375-402, 2010. https://doi.org/10.1007/978-3-642-02332-3_17

[9] Speight, J. G., 'Exploration'; In J. G. Speight, Subsea and Deepwater Oil and Gas Science and Technology. Elsevier, pp 107-126, 2015. https://doi.org/10.1016/B978-1-85617-558-6.00004-0

[10] Othman A. A., Fatty M. and Maher A.; Use of Spectral Decomposition technique for Delineation of Channels at Solar gas Discovery, Offshore West Nile Delta, Egypt. Egyptian Journal of Petroleum. 25(1):45-51,2016. https://doi.org/10.1016/j.ejpe.2015.03.005

[11] Morlet, J., Arens, G., Fourgeau, E. and Giard, D.; Wave propagation and sampling theory-Part II: sampling theory and complex waves: Geophysics, 47, 222-236, 1982. https://doi.org/10.1190/1.1441329 
[12] Partyka, G. A., Gridley, J. and Lopez, J.; Interpretational applications of spectral decomposition in reservoir characterization: The Leading Edge, 18, 353360,1999. https://doi.org/10.1190/1.1438295

[13] Marfurt, K.J., and Kirlin, R. L.; Narrow-band spectral analysis and thin-bed tuning: Geophysics, 66, 1274-1283, 2001. https://doi.org/10.1190/1.1487075

[14] Castagna, J.P., Sun, S. and Siegfried, R.W.; Instantaneous Spectral Analysis: Detection of low Frequency shadows associated with hydrocarbons. The Leading Edge, 22(2), 120-127, 2003. https://doi.org/10.1190/1.1559038

[15] Ghosh D., Viratna, B., Ibrahim, N.A. and Sajid M.; Seismic Attributes add a new Dimension to Prospect Evaluation \& Geomorphology Offshore Malaysia. The Leading Edge, 33(5):536-545, 2014. https://doi.org/10.1190/tle33050536.1

[16] Ejedawe, J.E., Patterns of incidence of oil reserves in Niger Delta Basin. AAPG Bulletin, 65:1574 - 1585, 1981. https://doi.org/10.1306/03B59620-16D1-11D7$\underline{8645000102 \mathrm{C} 1865 \mathrm{D}}$

[17] Tuttle, M. L. W., Charpentier, R. R. and Brownfield, M. E.; The Niger Delta Petroleum System: Niger Delta Province, Nigeria, Cameroon, and Equatorial Guinea, Africa. U. S. Geological Survey, Open-file Report-99-50-H. 4-22, 27-40, 1999. https://doi.org/10.3133/ofr9950H

[18] Reijers, T.J.A.' Stratigraphy and Sedimentology of Niger Delta. Geologos, 20117 (3): 133-162 2011. https://doi.org/10.2478/v10118-011-0008-3

[19] Doust, H. and Omatsola, M. E.; Niger Delta, In : J. D. Edwards, P. A Santogrossi (eds.), Divergent/passive margin basins. American Association of Petroleum Geologists; pp
239-248, 1990.

[20] Beka, F. T. and Oti, M. N.; 'The Distal Offshore Niger Delta Frontier Prospects of a Mature Petroleum Province,' In M. N. Oti and G. Postma, Eds, Geology of Deltas, A. A. Balkema, Rotterdam, pp 237-241, 1995.

[21] Mallat, S.; A wavelet tour of signal processing: Academic Press, 2nd edition, 1999. https://doi.org/10.1016/B978-012466606-1/50008-8

[22] Microsoft Encarta, "Reference Library Premium," DVD-ROM, 2006.

[23] Liu, J. and Marfurt, K. J., Matching Pursuit Decomcomposition using Morlet Wavelets, SEG Technical Program Extended Abstracts: 786-789, 2005. https://doi.org/10.1190/1.2148276

[24] Liu, J. and Marfurt, K. J., Multicolour Display of Spectral Attributes. The Leading Edge 26(6):268-271, 2007. https://doi.org/10.1190/1.2715047

[25] Marfurt, K. J., Techniques and Best Practices in Multiattribute Display. SEG Interpretation, 3(1):1F-T41, 2015. https://doi.org/10.1190/INT-2014-0133.1

[26] Chuang, H., and Lawton, D. C.; Frequency characteristics of seismic reflections from thin beds: Canadian Journal of Exploration Geophysics, 31: 3237,1995 .

[27] Widess, M.B.; How thin is a thin bed?: Geophysics, 38, 1176-1180, 1973. https://doi.org/10.1190/1.1440403

[28] Laughlin K., Garossino, P., Randy Ray, R. and Partyka, G., 'Spectral Decomposition for Seismic Stratigraphic Patterns', in Spectral Decomposition Applied to 3-D. AAPG Explorer Article, May 2002. 